\title{
Transnational Evaluation of a Continuing Professional Development Activity for Biomedical Scientists Based on the Clinical Laboratory Pre-analytical Phase
}

\author{
Jan Martin 1, *, Dorianne Buttigieg², Josef Silhavik ${ }^{3}$, Zlata Flegar-Meštrić ${ }^{4}$, Alison Adkins ${ }^{5}$, \\ Visnja Gasljevic ${ }^{6}$, Tomáš Š́lek ${ }^{7}$, Attila Horvath ${ }^{8}$, Charles Borg $^{2}$, Mladen Jakovcic ${ }^{6}$, \\ Adrienn Adonics ${ }^{8}$, Zsófia Szlamka ${ }^{8}$, Ian Brincat ${ }^{2}$, Noel Ciantar ${ }^{2}$, Anna Lisa Sciortino ${ }^{2}$, \\ Tracey Bennett ${ }^{9}$, Kirstie Rice ${ }^{10}$, Yvette Taylor $^{11}$ \\ ${ }^{1}$ Department of Biomedical Science and Physiology, University of Wolverhampton, Wolverhampton, United Kingdom \\ ${ }^{2}$ Department of Pathology, Mater Dei Hospital, L-Imsida, Malta \\ ${ }^{3}$ Department of Information Resources, Tomas Bata Regional Hospital, Zlin, Czech Republic \\ ${ }^{4}$ Department of Clinical Chemistry, University Hospital Merkur, Zagreb, Croatia \\ ${ }^{5}$ Department of Immunology, University of Birmingham, Birmingham, United Kingdom \\ ${ }^{6}$ Department of Training, Croatian Metrology Society, Zagreb, Croatia \\ ${ }^{7}$ Department of Clinical Biochemistry, Tomas Bata Regional Hospital, Zlin, Czech Republic \\ ${ }^{8}$ Department of Training, Horvath and Dubecz Consulting Ltd, Budapest, Hungary \\ ${ }^{9}$ Department of Microbiology, Royal Shrewsbury Hospital, Shrewsbury, United Kingdom \\ ${ }^{10}$ Department of Histology, New Cross Hospital, Wolverhampton, United Kingdom \\ ${ }^{11}$ Department of Newborn Screening and Biochemical Genetics, Birmingham Children's Hospital, Birmingham, United Kingdom
}

\section{Email address:}

j.martin@wlv.ac.uk (J. Martin), dorianne.buttigieg@gov.mt (D. Buttigieg), Josef.Silhavik@bnzlin.cz (J. Silhavik), zlata.mestric@zg.t-com.hr (Z.Flegar-Meštrić), A.E.ADKINS@bham.ac.uk (A. Adkins), visnja.gasljevic@hmd.hr (V. Gasljevic), tsalek@seznam.cz (T. Š́lek), HorvathA@hdkft.hu (A. Horvath), charles.m.borg@gov.mt (C. Borg),

mladen.jakovcic@hmd.hr (M. Jakovcic), adonics.adrienn@gmail.com (A. Adonics), szlamkazsofia@gmail.com (Z. Szlamka), ian.brincat@gov.mt (I. Brincat), noel.ciantar@gov.mt (N. Ciantar), anna-lisa.sciortino@gov.mt (A. L. Sciortino), Tracey.Bennett@sath.nhs.uk (T. Bennett), kirstie.rice@nhs.net (K. Rice), YVETTE.TAYLOR@bch.nhs.uk (Y. Taylor) ${ }^{*}$ Corresponding author

\section{To cite this article:}

Jan Martin, Dorianne Buttigieg, Josef Silhavik, Zlata Flegar-Meštrić, Alison Adkins, Visnja Gasljevic, Tomáš Šálek, Attila Horvath, Charles Borg, Mladen Jakovcic, Adrienn Adonics, Zsófia Szlamka, Ian Brincat, Noel Ciantar, Anna Lisa Sciortino, Tracey Bennett, Kirstie Rice, Yvette Taylor. Transnational Evaluation of a Continuing Professional Development Activity for Biomedical Scientists Based on the Clinical Laboratory Pre-analytical Phase. American Journal of Laboratory Medicine. Vol. 2, No. 6, 2017, pp. 126-131.

doi: 10.11648/j.ajlm.20170206.13

Received: February 20, 2017; Accepted: March 17, 2017; Published: October 31, 2017

\begin{abstract}
The 'Enhancing Hospital Laboratory Standards for Continuing Professional Development: A Quality Improvement Toolkit' project, which was funded by the European Union's Lifelong Learning Leonardo Program, has successfully developed several novel continuing professional development (CPD) activities for use by Biomedical Scientists within European hospital laboratories. This paper reports on transnational evaluation of the third European CPD activity which is based on the pre-analytical phase, by hospital laboratories in Croatia, Czech Republic, Malta and the United Kingdom.
\end{abstract}

Keywords: Continuing Professional Development, Training, Medical Laboratory Science, Biomedical Scientist, Pre-analytical 


\section{Introduction}

While a wide variety of different types of activities including work based learning, professional activity, formal/educational and self-directed learning [1], are appropriate for inclusion in a Biomedical Scientists continuing professional development (CPD) portfolio, for many Biomedical Scientists, CPD has mostly focussed on individual activities. Although in recent years there has been an increased emphasis for inclusion of reflection on CPD activities, again this has tended to be carried out on an individual basis. One of the main aims of this project was to bring Biomedical Scientists from different European countries together to learn from each other and to develop new CPD activities which could be carried out in groups where they could provide a platform for collaborative learning.

Collaborative CPD has been shown to be beneficial in a number of fields including education where it has been associated with enhancing teaching and learning and providing an opportunity for a variety of positive impacts on both teachers and students [2]. The benefit of collegial interaction as a method of CPD has also previously been highlighted in the healthcare arena where a group of general surgeons clinical expertise was enhanced by discussions with colleagues via videoconferencing [3].

This project sought to have CPD activites carried out by mutli-disciplinary groups of Biomedical Scientists in their own countries and to follow this up with interaction with the newly developed European Biomedical Scientist CPD Providers Community of Practice. European partner organisations from the University of Wolverhampton in the United Kingdom, Mater Dei hospital in Malta, Regional Hospital T Bati in Czech Republic, Croatian Metrology Society in Croatia and Horvath and Dubecz in Hungary received European Union funding to carry out the project entitled 'Enhancing Hospital Laboratory Standards for CPD: A Quality Improvement Toolkit'. Throughout the project, the partners shared and developed good practice in continuing professional development for biomedical scientists by collaboratively developing an EU-Toolkit [4] for delivery of high quality continuing professional development (CPD) activities for use by Biomedical Scientists within European hospital laboratories. A hospital laboratory CPD Providers Community of Practice network was also developed which included four exemplar hospital laboratory CPD activities based on active learning methods (Table 1). Partners carried out pilot trials $[5,6]$ of the new CPD activities in their own organisations with every pilot trial including evaluation by both trainees and trainers in partner countries.

Table 1. New CPD Activities Developed During the Project.

\begin{tabular}{ll}
\hline CPD Activity & Topic of CPD Activity \\
\hline 1 & Health and Safety [5] \\
2 & ISO 15189 [6] \\
3 & Pre-analytical phase \\
4 & Errors in Laboratory Medicine \\
\hline
\end{tabular}

Both the EU-Toolkit and the European Biomedical Scientist CPD Providers Community of Practice network are available at the Project's website and are accessible in all four partner languages: English, Czech, Croatian and Hungarian [7].

\section{Methods}

The 'Enhance It: Enhancing Hospital Laboratory Standards for CPD: A Quality Improvement Toolkit" EU funded project was a Leonardo Partnership between different organisations in five EU member countries as shown Table 2. The project which began during July 2013, ran for two years and was completed in July 2015. During the course of the project, which initially received funding of over 100,000 euros from the European Union's Lifelong Learning [8] Leonardo Partnership [9] Program, partner organisations worked together to develop an EU-Toolkit, a Community of Practice and several novel CPD activities. Throughout the project, transnational meetings were held in the UK [10] Croatia [11], Czech Republic [12], Hungary [13] and Malta [14].

Table 2. The Partner Organisations

\begin{tabular}{lll}
\hline EU Country & Organisation & Category of Partner \\
\hline Croatia & Croatian Metrology Society www.hmd.hr & Vocational Education and Training Provider \\
Czech Republic & Regional Hospital T Bata Inc http://www.kntb.cz/ & World of Work \\
Hungary & Horvath and Dubecz Consulting Ltd www.horvathesdubecz.hu & Vocational Education and Training Provider \\
Malta & Mater Dei Hospital https://health.gov.mt/en/MDH/Pages/Home.aspx & World of Work \\
United Kingdom & University of Wolverhampton www.wlv.ac.uk & Vocational Education and Training Provider \\
\hline
\end{tabular}

This paper is one of a series of studies which report on transnational evaluation of each of the novel CPD activities which were developed as part of the tangible outputs of the project. Both the first CPD activity which was developed by the UK [5] and the second CPD activity which was developed by Croatia [6] have already received very positive transnational evaluation. This current study is the third paper in the series and reports on evaluation of the third CPD activity which was developed by the Czech Republic.

In this study, a third CPD activity was developed for Biomedical Scientists on the topic of 'The Pre-analytical Phase'. Over 180 Biomedical Scientists from the partner countries of Croatia, Czech Republic, Malta and United Kingdom took part in the third CPD activity. At the beginning of the CPD session, Biomedical Scientists were required to answer the Pre-analytical questions in Table 3. In 
accordance with the format of the previous two CPD activities, on completion of the exercise participants were then organised into small groups where they were given the opportunity to discuss their findings with their colleagues. Biomedical Scientists then completed a reflective learning sheet which required them to reflect on what they had learned, how useful they felt that their learning from the CPD activity would be in their future day-to-day practice and to provide any suggestions for future development possibilities. At the end of the CPD session participants were required to complete an evaluation questionnaire (the questions are shown in Table 4).

Table 3. Pre-Analytical Questions.

\begin{tabular}{|c|c|c|}
\hline $\begin{array}{l}\text { Question } \\
\text { Number }\end{array}$ & \multicolumn{2}{|l|}{ Question } \\
\hline 1 & \multicolumn{2}{|c|}{$\begin{array}{l}\text { Part } 1 \text { - Patient Preparation } \\
\text { Is excercise allowed before taking samples for laboratory } \\
\text { tests? }\end{array}$} \\
\hline 2 & \multicolumn{2}{|c|}{ Can stress affect laboratory test results? } \\
\hline 3 & \multicolumn{2}{|c|}{$\begin{array}{l}\text { Is sex allowed before taking samples for laboratory } \\
\text { testing? }\end{array}$} \\
\hline 4 & \multirow{2}{*}{\multicolumn{2}{|c|}{$\begin{array}{l}\text { Is alcohol consumption advised before blood sampling? } \\
\text { Is eating allowed before taking samples for any laboratory } \\
\text { tests? }\end{array}$}} \\
\hline 5 & & \\
\hline 6 & \multicolumn{2}{|c|}{$\begin{array}{l}\text { Is it allowed to take antihypertensive drugs before blood } \\
\text { count testing? }\end{array}$} \\
\hline 7 & \multicolumn{2}{|c|}{$\begin{array}{l}\text { Is it advisable to drink water in the morning before blood } \\
\text { sampling? }\end{array}$} \\
\hline 8 & \multicolumn{2}{|c|}{$\begin{array}{l}\text { Is smoking allowed before taking samples for any } \\
\text { laboratory tests? }\end{array}$} \\
\hline 9 & \multirow{2}{*}{\multicolumn{2}{|c|}{$\begin{array}{l}\text { Can posture affect samples taken for laboratory sampling? } \\
\text { Is there an optimal time for the collection of laboratory } \\
\text { samples? }\end{array}$}} \\
\hline 10 & & \\
\hline & \multicolumn{2}{|c|}{ Part 2 - Quality of Sample (Text Questions) } \\
\hline 11 & \multicolumn{2}{|c|}{$\begin{array}{l}\text { Is a long tourniquet time (over } 1 \text { minute) optimal for blood } \\
\text { sampling? }\end{array}$} \\
\hline 12 & \multicolumn{2}{|c|}{$\begin{array}{l}\text { Is an open sampling system (syringe and needle) optimal } \\
\text { for blood sampling? }\end{array}$} \\
\hline 13 & \multicolumn{2}{|c|}{$\begin{array}{l}\text { Does the additive/preservative used or sample volume } \\
\text { affect laboratory test results? }\end{array}$} \\
\hline 14 & \multirow{4}{*}{\multicolumn{2}{|c|}{$\begin{array}{l}\text { When a cervical screening sample is taken, should an } \\
\text { endocervical sampling brush always be used to sample the } \\
\text { cervix in conjunction with a cervex brush for all samples. } \\
\text { Does the use of lubricant affect the quality of cervical } \\
\text { screening samples? } \\
\text { A Cerebral Spinal Fluid (CSF) is received from a patient } \\
\text { with the clinical history querying bacterial meningitis and } \\
\text { it is stated that antibiotic treatment has begun. Is this } \\
\text { sample suitable for bacterial culture? } \\
\text { Part } 3 \text { - Quality of Sample (Photo Questions) }\end{array}$}} \\
\hline 15 & & \\
\hline 16 & & \\
\hline & & \\
\hline 17 & & Is this sample safe for laboratory staff? \\
\hline 18 & & $\begin{array}{l}\text { Is this a suitable sample for blood gas } \\
\text { analysis? }\end{array}$ \\
\hline
\end{tabular}

Question
Are the patient details clearly
identifiable?

\section{Results}

This paper reports on the third stage of the Leonardo Partnership Project entitled 'Enhance It' which involved transnational evaluation of a third CPD activity by hospital laboratories in Croatia, Czech Republic, Malta and the United Kingdom.

Over one hundred and eighty Biomedical Scientists from four different European countries Croatia $(n=11)$, Czech Republic $(n=9)$, Malta $(n=137)$ and UK $(n=26)$ took part in this new CPD activity. Biomedical Scientists evaluated the activity and indicated (Table 4 ) that the exercise had been useful and appropriate to their scope of practice (82.4\%) and relevant for their own CPD (83.1\%). Discussion with colleagues following completion of the activity provided useful enhancement to both scope of practice $(75.2 \%)$ and CPD (89.5\%). Subsequent completion of a reflective learning sheet was shown to be beneficial for $89 \%$ of participants and over $97 \%$ of Biomedical Scientists rated the exercise overall as good or excellent. Responses indicated that the CPD activity could have been enhanced by clearer photos, more 
difficult questions and the inclusion of a questions covering a wider range of laboratory disciplines.

Table 4. Responses to Evaluation Questions.

\begin{tabular}{|c|c|c|c|c|c|}
\hline Question & Response & $\begin{array}{l}\text { Croatia \% } \\
\mathrm{n}=11\end{array}$ & $\begin{array}{l}\text { CZE \% } \\
\text { n }=9\end{array}$ & $\begin{array}{l}\text { Malta \% } \\
\text { n }=137\end{array}$ & $\begin{array}{l}\text { UK \% } \\
n=26\end{array}$ \\
\hline \multirow{6}{*}{$\begin{array}{l}\text { Do you feel that the exercise is useful and/or appropriate } \\
\text { to your scope of practice? }\end{array}$} & Strongly Agree & 100 & 44 & 44 & 0 \\
\hline & Agree & 0 & 56 & 47 & 23 \\
\hline & Neither Agree nor Disagree & 0 & 0 & 7 & 8 \\
\hline & Disagree & 0 & 0 & 2 & 50 \\
\hline & Strongly Disagree & 0 & 0 & 0 & 19 \\
\hline & Answer Not Given & 0 & 0 & 0 & 0 \\
\hline \multirow{5}{*}{ Is the format of this exercise new to you? } & Agree & 0 & 33 & 32 & 19 \\
\hline & Neither Agree nor Disagree & 0 & 22 & 11 & 8 \\
\hline & Disagree & 100 & 22 & 35 & 38 \\
\hline & Strongly Disagree & 0 & 0 & 8 & 31 \\
\hline & Answer Not Given & 0 & 0 & 4 & 0 \\
\hline How long did it take to complete this exercise? & Time Taken in minutes (mean) & 30 & 20 & 118 & 25 \\
\hline \multirow{2}{*}{$\begin{array}{l}\text { Do you feel that this is relevant CPD? Please explain } \\
\text { why/why not/ }\end{array}$} & Yes & 100 & 100 & 92 & 23 \\
\hline & Answer Not Given & 0 & 0 & 0 & 4 \\
\hline \multirow{2}{*}{$\begin{array}{l}\text { Were instructions easy to follow/understand? If not, what } \\
\text { would have helped? }\end{array}$} & Yes & 100 & 100 & 94 & 65 \\
\hline & No & 0 & 0 & 6 & 35 \\
\hline \multirow{3}{*}{$\begin{array}{l}\text { Was the discussion element useful to your scope of } \\
\text { practice? }\end{array}$} & Yes & 0 & 0 & 91 & 50 \\
\hline & No & 100 & 100 & 9 & 35 \\
\hline & Answer Not Given & 0 & 0 & 0 & 15 \\
\hline \multirow{3}{*}{ Was the discussion element useful to your CPD? } & Yes & 100 & 100 & 96 & 47 \\
\hline & No & 0 & 0 & 4 & 38 \\
\hline & Answer Not Given & 0 & 0 & 0 & 15 \\
\hline \multirow{3}{*}{ Was the reflection/reflective sheet useful to your CPD? } & Yes & 100 & 100 & 92 & 65 \\
\hline & No & 0 & 0 & 8 & 23 \\
\hline & Answer Not Given & 0 & 0 & 0 & 12 \\
\hline \multirow{4}{*}{ Overall how would you rate the complete CPD exercise? } & Excellent/Very useful & 100 & 0 & 92 & 0 \\
\hline & Good/Useful & 0 & 100 & 8 & 74 \\
\hline & Poor/Not Useful & 0 & 0 & 0 & 0 \\
\hline & Question Not Answered & 0 & 0 & 0 & 26 \\
\hline
\end{tabular}

\section{Discussion}

With regard to the topic of the third CPD activity, most Biomedical Scientists agreed that the topic of 'Pre-analytical Phase' was directly related to their work, was very relevant and that it had been helpful to refresh their knowledge and gain a better understanding of the subject. One Biomedical Scientist also commented that the

'Pre-analytical phase is very important but not always considered as such ... this is important information that laboratory staff should know.'

The format of the CPD activity was well received by Biomedical Scientists in all European Union partner countries. They appreciated the interesting interactive approach which proved to be beneficial as it included a discussion element which was felt to be very important. Although a few of the CPD questions were perceived by some participants as being oversimplified, others liked the format of.

'simple questions which make you research the answer and [facilitate] learning on the way'.

Suggested improvements which were put forward included having more in depth case studies, more challenging questions and the use of.

'online learning [with a] conference call meeting with all countries involved'.

There were three main important themes emphasized by participants deuring evaluation of the pre-analytical CPD activity namely; collaborative learning, the value of a mulitidisciplinary learning approach and the impact on day to day practice of the learning undertaken and knowledge gained.

Collaborative learning has previously been shown to assist science teachers with their professional development in the area of technological, pedagogical and content knowledge by providing a platform for swapping and refining ideas [15]. In the current study, similar beneficial aspects of the collaborative approach to CPD employed in this activity were highlighted by several participants who commented on the advantages of an interactive session. One of the beneficial themes of the collaborative learning environment which was highlihted by several participants was that of enhanced learning when compared to the usual passive listening CPD sessions which they usually attended. One of the participants commented that the session had been.

'highly appropriate as one learns more through discussion'

while other Biomedical Scientists supported that view and stated that

it teaches things that are not so easily learned through study' 
which in turn

\section{'promotes thought and research'}

The positive aspects of learning within a multidisciplinary arena were highlighted by several Biomedical Scientists. One of the participants stated that

'the exercise was very helpful especially in my case as I don't practice in clinical chemistry or haematology and it permitted me to understand better some concepts related to blood sampling'

and another Biomedical Scientist commented that

'I learned some issues which I dIdn't know beforehand, especially concerning tests in other labs'

whereas the comparison between the different laboratory disciplines was the focus of a further feedback comment

'it was interssting to realise that things that other laboratories encounter every day and are important for them but are insignificant for us

While one of the main aims of CPD is for it to lead to a positive influence on day-to-day practice, the impact of CPD can be difficult to measure [16]. Many factors have been shown to influence its impact including; the regulatory context within the dental profession [17] and social processes within aspiring school principals [18]. Novel ways of measuring the impact of CPD have been developed including production of a score sheet for use by pharmacists to enable quantification of the impact and relevance of their CPD [19]. In the current study Biomedical Scienctists were asked to make an individual assessment of the impact of this CPD activity on their own daily practices. The results were very positive with Biomedical Scientists commenting that they would apply learning from the CPD session when comparing the results from two different laboratory disciplines and feedback stating that they would.

'practise daily what I've learnt today!'

Prior to implementation of this project, EU hospital laboratories didn't collaborate on development of their locally delivered CPD activities despite the fact that they are significant providers of CPD activities for Biomedical Scientists. This project has initiated European co-operation for partner organisations, staff and employees and has brought together Biomedical Scientists and CPD providers from partner countries to work, learn and cooperate jointly. As such it has forged an intensive network of European collaboration of Biomedical Scientists and trainers who are all striving to harmonise their practice throughout the EU.

\section{Conclusions}

We conclude that implementation of this novel CPD activity on the topic of the clinical laboratory pre-analytical phase has been one of the key elements of this project which has served to intensify European biomedical science CPD, associations and partnerships. The project overall has had immense success in bringing together a European Community of Practice intent on fostering teamwork and building new working relationships within a network of European hospital laboratories.

\section{Acknowledgements}

The authors wish to acknowledge the European Lifelong Learning Leonardo Partnership grant for funding the project (Reference number LdVP/13/006C) and Dr. Pavel Šafařík and Miroslav Srcháček from The Department of clinical biochemistry in Tomas Bata Hospital Inc. in Zlin and Mgr. Kateřina Hromada from The Department of Pathology from the hospital in Vsetin for taking most of the photographs.

\section{References}

[1] HCPC Your guide to our standards for continuing professional development.

http://www.hcpcuk.org/assets/documents/10003B70Yourguide toourstandardsofcontinuingprofessionaldevelopment.pdf

[2] Cordingley P, Bell M, Rundell B, Evans D (2003) The impact of collaborative CPD on classroom teaching and learning. In: Research Evidence in Education Library. Version 1.1*. London: EPPI-Centre, Social Science Research Unit, Institute of Education.

[3] Gagliardi, A. R., Wright, F. C., Anderson, M. A. B. and Davis, D. (2007), the role of collegial interaction in continuing professional development. J. Contin. Educ. Health Prof., 27: 214-219. doi: 10.1002/chp.140.

[4] Martin J et al., (2014) Transnational Evaluation of an EUtoolkit To Enhance Continuing Professional Development for Specialists in Laboratory Medicine. $31^{\text {st }}$ World Congress of Biomedical Laboratory Science Taiwan, for October 2014.

[5] Martin J, Buttigieg D, Silhavik J et al (2014) Enhance It Enhancing Hospital Laboratory Standards for Continuing Professional Development: Transnational Evaluation of a Novel CPD Activity for Biomedical Scientists. American Journal of Educational Research 2 (11) 1110-1114.

[6] Martin J, Buttigieg D Silhavik J et al (2015) Transnational Evaluation of a New Continuing Professional Development Activity for Biomedical Scientists Based on the International Organisation for Standardisation for Medical Laboratories ISO 15189. American Journal of Educational Research, 3 (5), 637-642.

[7] 'Enhance It' project website http://www.enhanceit.eu/.

[8] The European Union Lifelong Learning Programme https://www.lifelonglearningprogramme.org.uk/.

[9] Leonardo Partnerships.

[10] http://www.leonardo.org.uk/default.asp?section=00010001\&s ectionTitle=Home.

[11] [10]Martin J (2014) First Transnational Meeting of a European Project to Enhance Hospital Laboratory Standards for Biomedical Scientist's CPD by Developing a Quality Improvement Toolkit. The Biomedical Scientist, 58 (5).

[12] Martin J, Adkins A, Bennett T, Rice K and Taylor Y. (2014) European Project to Enhance Standards for Biomedical Scientist CPD: Developing a Quality Improvement Toolkit. The Biomedical Scientist 58 (6) 321-323. 
[13] Martin J (2014) European Project to Enhance Laboratory Standards for Biomedical Scientist CPD: Third Transnational Meeting. The Biomedical Scientist 58 (10) 550-551.

[14] Martin J, Adkins A, Bennett T, Rice K and Taylor Y. (2015) European Project to Enhance Laboratory Standards for Biomedical Scientist CPD: Fourth Transnational Meeting. The Biomedical Scientist 59 (3).

[15] Martin J, Gasljevic V, Šálek T et al (2015) Laboratory Standards for Biomedical Scientist's Continuing Professional Development: Fifth European Transnational Meeting The Biomedical Scientist 59 (6) 330-331.

[16] Chen, Y-H.; Jang, S-J.; Chen, P-J.(2015) Using Wikis and Collaborative Learning for Science Teachers' Professional Development. Journal of Computer Assisted Learning, 31 (4): 330-344.

[17] Goodall J, Day C, Lindsay G Muijs D, Harris A (2005)
Evaluating the Impact of CPD

http://www2.warwick.ac.uk/fac/soc/cedar/projects/completed0 5/contprofdev/cpdfinalreport05.pdf.

[18] Bullock, A; Firmstone, V; Frame, J; Thomas, H (2010). Using Dentistry as a Case Study to Examine Continuing Education and Its Impact on Practice. Oxford Review of Education, 36 (1): 79-95.

[19] Reeves, J; Morris, B; Forde, C; Turner, E (2001) Exploring the Impact of Continuing Professional Development on Practice in the Context of the Scottish Qualification for Headship. Journal of In-service Education, 27 (2): 203-220.

[20] Donyai, P; Alexander, A M.; Denicolo, P M. (2013) A Framework for Assessing Continuing Professional Development Activities for Satisfying Pharmacy Revalidation Requirements. Journal of Continuing Education in the Health Professions, 33 (2): 127-135. 